\title{
Challenges in the development of analytical test procedure for aminoglycosides: A critical review
}

\author{
Radhakrishnan Hari, Shaik Taherunnisa, Sushil Yadaorao Raut, Srinivas Mutalik, Kunnatur B. Koteshwara* \\ Department of Pharmaceutics, Manipal College of Pharmaceutical Sciences, Manipal Academy of Higher Education, Manipal 576104, India.
}

\section{ARTICLE INFO \\ Received on: 29/05/2019 \\ Accepted on: 18/09/2019 \\ Available online: 04/11/2019}

\section{Key words:}

Aminoglycosides, antibiotics, analytical methods,

impurities.

\begin{abstract}
The present article reviews the challenges and hurdles in the development of an analytical method for aminoglycosides (AG). The article emphasizes on the attempts made to develop analytical methods based on HPLC and other sophisticated techniques, such as LC-MS, radioimmunoassay, microbial assay, enzyme linked immunosorbent assay (ELISA), extractive colorimetry, anion-exchange chromatography with pulsed amperometric detection, high performance thin layer chromatography, densitometry, and microbial agar diffusion assay. The various media mostly used for the in vitro as well as in vivo estimation of AG by HPLC and LC-MS are heptafluorobutyric acid, ammonium acetate, ammonium formate and formic acid. Estimation of AG by radioimmunoassay and ELISA can be suitably done by using TRIS-HCl and saline phosphate buffer. The buffer media used for ex vivo analysis mostly include MEM, TRIS and saline phosphate. The presence of AG in food from the animal sources, water bodies, and its prolonged exposure may result in serious health issues. The present article outlined the various sensitive, robust and precise analytical techniques for the estimation of the various aminoglycosides in many sources, and discussed the hurdles faced during the development of the analytical techniques.
\end{abstract}

\section{INTRODUCTION}

Aminoglycosides (AG) are broad-spectrum antibiotics, discovered in the year 1944 with streptomycin being the first molecule. Streptomycin is a water-soluble molecule, which is active against Gram-negative bacteria but when the bacteria started showing the resistance toward the molecule, kanamycin was identified in the year 1954 which was active against the streptomycin resistant bacteria (Farouk et al., 2015). Later, the mechanism behind the bacterial resistance was identified and was resolved by developing many semi-synthetic AG, namely, amikacin, dibekacin, gentamicin, kanamycin, neomycin, netilmicin, paromomycin, sisomicin, streptomycin, dihydrostreptomycin, and tobramycin being currently used (McGlinchey et al., 2008).

The word aminoglycoside originates from its structuretwo amino sugars are joined together through a glycosidic

\section{"Corresponding Author}

Kunnatur B. Koteshwara, Department of Pharmaceutics, Manipal College of Pharmaceutical Sciences, Manipal Academy of Higher Education, Manipal 576104,India.E-mail:kb.koteshwara@manipal.edu linkage to an aminocyclitol. The aminocyclitol unit can be 1,3 or 1,4 di-substituted, based on which it is divided into two (i) 2-deoxy streptamine (ii) streptamine. The 2-deoxy streptamine is further divided into two based on the number and the position of substituent attached (Isoherranen and Soback, 1999).

The AG are produced from the natural source through fermentation, mainly from Streptomyces and Micromonospora species of bacteria. Based on the source from which it originates the antibiotics are given suitable names. The antibiotics from Streptomyces species are given "mycin" as a suffix and those from Micromonospora are given "micin" as a suffix (Farouk et al., 2015).

The AG has potential veterinary application in treating the bacterial infections due to bacterial enteritis (scours) and mastitis; these are added with the feed for the prophylaxis or as growth promoters. These days it is not allowed to use aminoglycoside as growth promoters according to the European legislation. The commonly used aminoglycoside for the veterinary purpose includes gentamicin, neomycin, dihydrostreptomycin, and streptomycin (Stead, 2000). 
The AG are poorly absorbed from the intestine/gut after oral or rectal administration. So, it is given as an intramuscular or intravenous injection. They are poorly bound to plasma protein and get excreted through renal route mainly by the glomerular filtration. The plasma half-life of the drug is only 2 hours, but it is found to be sufficient to be administered once in a day (Forge and Schacht, 2000)

\section{NEED FOR THE ANALYTICAL METHODS}

For the characterization of a new molecule from the fermentation, the analytical methods have a broader sense of application. (e.g., TLC). For the therapeutic drug monitoring, the quantitative determination of AG in the biological samples are done by an analytical technique which serves as a guide for drug dosing and to reduce toxicity. During pharmacokinetic and other research studies, the level of AG is determined in various biological and tissue fluids. Hence, to apply these analytical methods for these various purposes, it should be sensitive and specific enough. At present, HPLC serves to meet these requirements (Tawa et al., 1998). The analytical method should be sensitive enough to detect the veterinary drug residue, from the food of animal origin. They are used by various regulatory bodies to ensure food safety and to enforce regulations that serve as a guide for the usage of drugs in animals (Carlier et al., 2015).

The microbial assay is preferred as a screening method for drug residue present in food of the animal origin; it can detect the presence of all class of antibiotics at one shot. For the confirmation on what type of residue, hyphenated methods, such as GC-MS or HPLC-MS, are used. The method finds its application in the analysis of bulk pharmaceuticals, stability studies, quality control, etc.

\section{CHALLENGES INVOLVED IN THE DETERMINATION OF AG}

With the wider area of application, the analytical methods have a greater role to play in AG analysis. At the same time next to the application, it put forward some important general issues. The AG because of its high polar nature, in aqueous liquids they are present as polyionic forms, therefore the extraction or preconcentration is difficult to achieve. The AG when considered are having a weak chromophore or fluorophore, hence rules out the possibility of direct analysis by HPLC with UV or Fluorescence detector (Farouk et al., 2015; McGlinchey, 2011). AGs demonstrate bad retention features in RPLC due to their extremely polar character, i.e., in-solution protonated species in the relevant $\mathrm{pH}$ range. It seems that the use of ion-pair fluid chromatography or HILIC is the simplest way to fix this issue. Some trials have used an elevated $\mathrm{pH}$ mobile phase to make $\mathrm{AG}$ a unionized molecule that demonstrates RPLC retention. Thus, that retention makes easy detection as well as quantification of the AG in various samples (Tan et al., 2012). AG detection and quantification relies mainly on the particular region of implementation. If the purpose of the evaluation is to determine degradation products or impurities, derivation may trigger unwanted or unexpected changes to unknown impurities or degradation products. Due to lack of chromophore, volatility, and high water solubility of AGs, it found to be difficult to analyse. Thus, many researchers adopted the derivatization techniques (Isoherranen \& Soback, 1999). Holzgrabe et al. (2011) developed the HPLC method for streptomycin sulfate and reported the use of penta-fluoro-propionic anhydride as mobile phase with high column temperature conditions in order better resolution takes place through the efficient ion pairing. Pre-derivatization or post-derivatization methods was used to HPLC and LC-MS applications. Pang et al. (2004) estimated streptomycin in honey samples by using post-derivatization technique and analyzed by using liquid chromatography. It has been found that the recoveries obtained from $73.7 \%-78.5 \%$ along with the relative standard deviations of $1.64 \%-3.80 \%$. The relative stability of aminoglycoside in the honey samples was determined by this technique. The streptomycin was stable in honey samples (Pang et al., 2004). The environmental impact of the use of AG is stirring the world due to enormous veterinary. That has been adversely affecting the human life indirectly due to the consumption of animal products and also affects the economic status. Thus, it is necessary to estimate the residual content of AGs in various foodstuffs from animal sources. The currently available analytical techniques are quite expensive and time consuming (Krause et al., 2016). Other than these aspects, there are various challenges involved in the analysis of AG are given in Figure 1.

\section{AG as residues in food substance from animal origin}

The analysis of AG in food substance is challenging since the type of antibiotic is unknown and its level of presence is also unknown. Therefore, initially, a screening method must be applied to confirm its presence followed by the application of a quantitative method. Here, it put forwards challenges in the extraction and both detection and quantification (Isoherranen and Soback, 1999; Mucklow, 2004).

In the developing countries, strict documentation on residual analysis and enforcement of the law on food safety are less common, unlike European Union. At present, a maximum residual

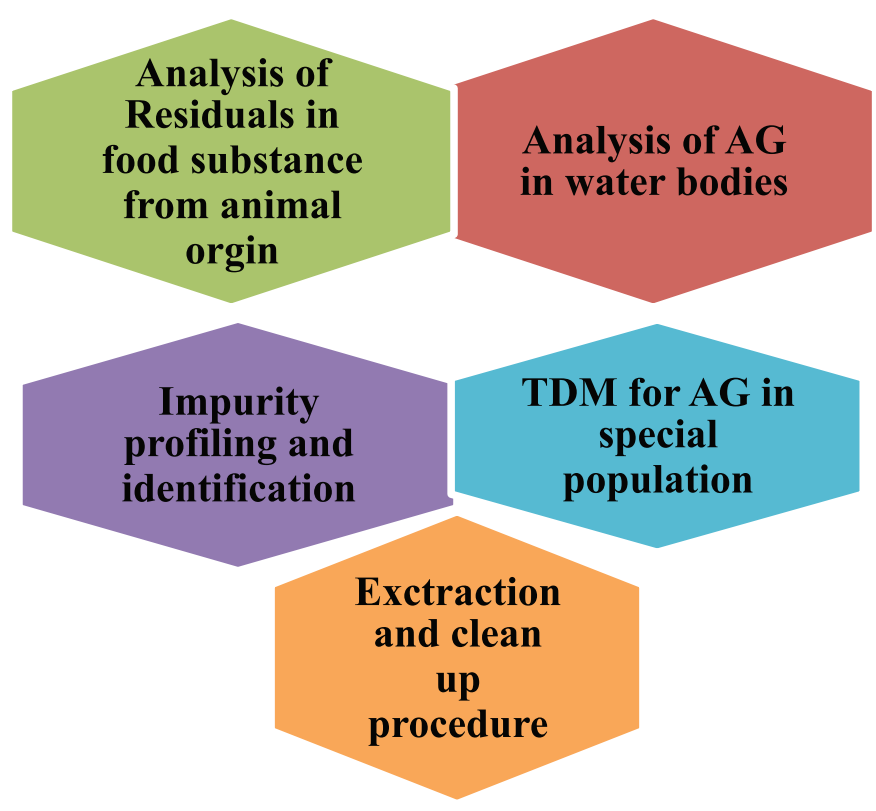

Figure 1. Challenges involved in AG analysis. 
limit (MRL) has been established compared to zero AG residual limits in the past. These regulatory bodies have established the residual limit for AG in milk, edible tissue, and other foodstuff (Farouk et al., 2015). The residual limits for AGs in food from animal origin are given in Table 1.

To ensure that the food substance from the animal origin meets the accepted MRL the analyst must develop a fast and economical method to analyze the sample instantaneously, which help them to grade and prohibit if found to have residuals above the accepted limit. The analytical methods employed are divided as screening method where the residue should be less than the detection limit and, quantitative method.

\section{AG as residue in water}

The antimicrobials like AG when administered are excreted unchanged from human body and animals, in addition to this the disposal of medical waste deliberately or non-deliberately from the medical industry to the surface water has increased the level of contamination compared to the past.

In case of analysis for residuals in water, the major challenge involved is in pre-concentrating the sample so that the content is in the required detection limit. As per the report published by the International Joint Commission, only $50 \%$ of the medical wastes are removed through sewage treatment before disposal into water bodies. In the developing countries, sewage water treatment is an important concern where health and environmental shortcomings are present. The presence of antibiotics in the water will affect the aquatic environment too. As mentioned preconcentrating the sample remains the major challenge, e.g., the use of solid phase extraction by using a cationic exchanger is employed in the analysis of Gentamicin in hospital wastewater. The immunoassay like enzyme linked immunosorbent assay (ELISA) is a reported method for screening of AG, such as streptomycin, neomycin, and gentamicin. Considering the presence of weak chromophore, the spectroscopic method is applicable only after derivatization. It has been reported that the method is applicable only to a dynamic range but not up to the residual limit in $\mathrm{ng} / \mathrm{kg}$; therefore, the LC remains the most appropriate method (Forge and Schacht, 2000).

\section{Profiling impurities and its identification}

The AG is mostly present as a mixture of components. For instance, if we take gentamicin the compound is present as a mixture of isomeric components called gentamicin complex. The components namely are gentamicin $\mathrm{C} 1, \mathrm{C} 1 \mathrm{~A}, \mathrm{C} 2 \mathrm{~A}, \mathrm{C} 2$, and $\mathrm{C} 2 \mathrm{~B}$. The problem associated in such case during method development is, the individual standard for each of the components are not available for comparison. The order of elution is made based on the existing literature or based on compendial data (Stypulkowska et al., 2010).

When it comes to the related substance of AG, most of them are difficult to separate and some are yet to be discovered. If we take gentamicin itself, the US pharmacopoeia mentions four related substance for gentamicin, but only for two substances, the individual standard is available and are included in the pharmacopoeia method (Clarot et al., 2004).

In the developing countries like India, profiling impurities are of at most important where the local industries prefer to procure raw materials of poor quality from which the final product is also made. The current methods may not be sufficient to detect these impurities sometime and, with respect to $A G$, the situation is more demanding and challenging, hence sophisticated instruments are used. The current reported methods for AG include LC-MS, LC-ELSD, etc. The microbial assay is recommended as a determination method for gentamicin by WHO (Farouk et al., 2015).

\section{Therapeutic drug monitoring (TDM) for AG}

The AG at present are used to treat serious infection caused due to Gram-negative bacteria. Though newer and less toxic antibiotics are available, the $A G$ remain the choice for serious infection. TDM for AG are important since they have a short therapeutic range. The abusive use of AG will have potential side effects, such as ototoxicity, nephrotoxicity, and neuromuscular paralysis (Carlier et al., 2015).

To maintain an adequate plasma level and to avoid toxicity, TDM of AG is important. The therapeutic window of AG is less; moreover, the excretion depends greatly on the renal function. Therefore, variation in the plasma concentration exists

Table 1. Residual limits of various AGs in food materials.

\begin{tabular}{|c|c|c|c|c|c|}
\hline \multirow{2}{*}{ Aminoglycosides } & \multicolumn{4}{|c|}{ Residual limits ( $\mu \mathrm{g} / \mathrm{kg})$} & \multirow{2}{*}{ References } \\
\hline & Meat & Milk & Eggs & Honey & \\
\hline Streptomycin & 500 & 200 & - & 40 & Ferguson et al., 2002 \\
\hline \multirow{2}{*}{ Gentamycin } & \multirow{2}{*}{2.7} & \multirow{2}{*}{200} & \multirow{2}{*}{ - } & \multirow{2}{*}{-} & Chen et al., 2008 \\
\hline & & & & & Tan et al., 2009 \\
\hline Neomycin & 500 & 1,500 & 500 & - & Jin et al., $2006 \mathrm{~b}$ \\
\hline \multirow[t]{3}{*}{ Kanamycin } & \multirow[t]{3}{*}{50} & \multirow[t]{3}{*}{150} & \multirow[t]{3}{*}{0.01} & \multirow[t]{3}{*}{-} & Loomans et al., 2003 \\
\hline & & & & & Bousova et al., 2013 \\
\hline & & & & & Jiang et al., 2019 \\
\hline \multirow[t]{2}{*}{ Tobramycin } & \multirow[t]{2}{*}{$0.61 \times 10^{-3}$} & \multirow[t]{2}{*}{0.548} & \multirow[t]{2}{*}{-} & \multirow[t]{2}{*}{-} & Jiang et al., 2018 \\
\hline & & & & & Pavlov, 2005 \\
\hline Spectinomycin & 5,000 & 200 & - & - & Di Corcia et al., 2002 \\
\hline Apramycin & 5,000 & & - & - & Di Corcia et al., 2002 \\
\hline Paromomycin & 1,500 & 100 & - & - & Bohm et al., 2013 \\
\hline
\end{tabular}


from patients to patients, e.g., in elderly and renal impaired patients. Hence in hospitals, a suitable method for its analysis is required for constant plasma concentration monitoring.

The current analytical methods for TDM is microbial assay, HPLC method with UV detector is reported (Li et al., 2012), LC-MS and GC-MS. The preferred method used is immunoassay and is the official assay method by USP-NF. The common problem faced during immunoassay is interference due to inhibitors and other degradation products. The HPLC method with UV detector is reported for the analysis, but the absence of chromophore makes the process of analysis more critical and complex due to the involvement of derivatization.

In recent time, computer-based software, such as Aladdin $^{\circledR}$, TCIWorks ${ }^{\circledR}$, or SeBagen ${ }^{\circledR}$, has been utilized to calculate pharmacokinetics by two sample measurements for aminoglycoside. This software can also suggest future dosing compared to dosage adjustment from the obtained data in the conventional method (trial and error until a steady state) (Reeves, 1980).

\section{EXTRACTION AND CLEAN-UP PROCEDURE}

The AG due to their physio-chemical property put forward some challenges in the extraction and clean up before application of the analytical method to the biological samples. The properties, such as basicity, high water solubility, and hydrophilicity, make AG highly susceptible to photodegradation making the sample extraction process complex (Santos and Ramos, 2016). Moreover, the selective removal of possible interfering substance in a biological sample is difficult to achieve (Reeves, 1980).

\section{General procedure for the extraction}

The general procedure for the extraction of AG from the tissue is shown in Figure 2. It involved the tissue homogenization by using the suitable homogenizer. Protein precipitation from the tissue homogenate can be performed with the addition of chilled methanol or acetonitrile along with the vigorous mechanical shaking. Later, the sample can be centrifuged or settled down to separate the precipitate from the supernatant.

\section{METHODS FOR ANALYSIS OF AG}

The analytical method involved in the analysis of AG can be divided into two, qualitative method and quantitative method.

\section{Quantitative method}

As the AGs having poor oral bioavailability, it's detection and quantification in plasma is challenging due to less drug availability. Thus, the quantitative analysis of AGs in plasma or tissue from the oral dosage forms (solid) is quite tough as compared to the parenteral dosage forms. Thus, the very sensitive analytical technique with very low limit of detection as well as quantification will be expected to develop (Omar et al., 2013). The quantitative method for $A G$ includes microbial and liquid chromatographic method. The microbial assay remains as a traditional method for assay. The microbial method is used for the estimation of AG potency by comparing the area of inhibition of microbial growth for a known amount of test sample in a biological medium and a reference substance. The method is inexpensive and easy to perform but is subjected to interference by other inhibitors. It has been reported that the microbial assay fails to meet the acceptance criteria for precision and accuracy in the analysis of neomycin; hence, the monograph method has been changed to LC method (Gunawardana et al., 1997). The AG being hydrophilic in nature does not strongly bind to the protein in the matrix, which makes the microbial method challenging. The other microbial methods include radioimmunoassay, radiochemical assay, and enzymelinked immunosorbent assay. The various quantitative analytical techniques reported are given in Table 2.

These methods are highly sensitive and precise; but they possess drawbacks like high equipment cost, difficulty in handling of radioactive substances. Like microbial assay, cross-reactivity is observed in these methods too. Physio-chemical property of AG put forward challenges in development and use of the LC method. The highlighted challenges have already been covered in the previous section of this article. The challenges faced during the development of the method have been resolved and adequate literature has been published. The absence of the chromophore in

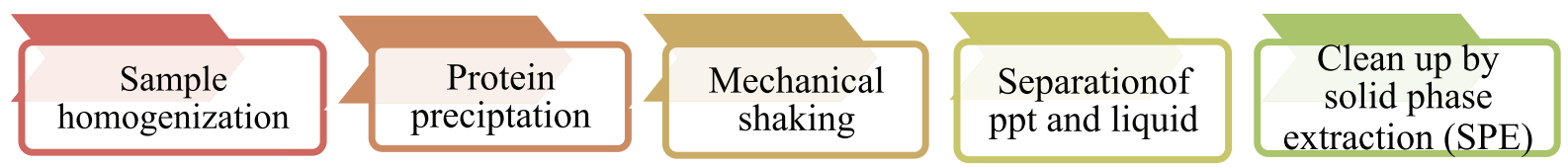

Figure 2. General procedure for the extraction of AG from the tissue.

Table 2. Reported analytical techniques for various AGs.

\begin{tabular}{|c|c|c|}
\hline Types of AG & Reported quantitative analytical techniques & References \\
\hline Tobramycin & RP-HPLC, RP-HPLC-MS, Radioimmuno assay, HPLC-ELSD & $\begin{array}{l}\text { (Ruckmani et al., 2011; Guo et al., 2006; Broughton } \\
\text { et al., 1976; Megoulas and Koupparis, 2005b) }\end{array}$ \\
\hline Streptomycin & RP-HPLC, LC-MS/MS & (Granados and Meza, 2007; Bohm et al., 2012) \\
\hline Amikacin & LC-MS, RP-HPLC, & (Dijkstra et al., 2014; Teja et al., 2018) \\
\hline Kanamycin & $\begin{array}{l}\text { HPLC-NQAD (nano quantity analyte detector) and HPLC-ELSD, Colorometric } \\
\text { estimation, }\end{array}$ & $\begin{array}{l}\text { (Zhu et al., 2014; Hussien et al., 2017; Dijkstra et al., } \\
\text { 2016) }\end{array}$ \\
\hline Gentamycin & Microbial assay and RP-HPLC, ELISA, Extractive colorimetry & $\begin{array}{l}\text { (Kumar and Ramya, 2012; Brion et al., 2002; Fraihat, } \\
\text { 2015) }\end{array}$ \\
\hline Neomycin & HPTLC and densitometry, microbial agar diffusion assay, HPLC-ELSD & $\begin{array}{l}\text { (Hubicka et al., 2015; Yamamoto and Pinto, 1996; } \\
\text { Zhang and Zhang, 2007) }\end{array}$ \\
\hline
\end{tabular}


AG is overcome using universal detectors like CAD, ELSD and RI detector (Clarot et al., 2004; Li et al., 2012; Samain et al., 1987) or can be applied to UV/Fluorescence detector by pre or post-column derivatization (Kowalczuk et al., 2010).

The choice between the pre and post-column derivatization is done based on a few factors, such as desired sensitivity, sample size, and instrument availability. The precolumn derivatization is simple compared to post column derivatization were complex instrumentation is required.

The process of derivatization is basically achieved by modifying the primary amine group present. The various agents used include fluorenylmethyloxycarbonyl chloride, dansyl chloride, 1-fluoro-2,4-dinitrobenzene, and o-phthalaldehyde (OPA). The OPA is commonly used in both pre and post-column derivatization, in which it reacts with a primary amine in an aqueous basic medium ( $\mathrm{pH} 9-11)$ in the presence of mercaptans to give an isoindole derivative (Coppex and Walz, 2000). Hence, this enables the use of RP-HPLC rather than complex ion pair liquid chromatography (IP-LC) method.

The process of derivatization always remains critical with few drawbacks, such as loss of analyte due to additional treatment step, incomplete reaction, formation of the unstable product, and insufficient reaction time are present. The post column derivatization is generally limited in use due to a various additional complex process.

The LC-MS is widely applied for the analysis of AG. The challenge faced during the analysis is, upon fragmentation the different ion of AG show almost the same mass to charge ratio due to high structural similarity. This is to be added to the challenges in LC separation, already addressed in the previous section. Thus, care should be taken to avoid interference in the selection of product- ion combination or precursor-ion for selected reaction monitoring. As per the problems associated with the estimation of AG by using current analytical techniques, the alternatives methods has been developed and are in progress of modifications in order to easy and effective quantification. These methods are quite expensive due to involvement of additional steps and chemicals. Methods like use of molecularly imprinted polymers for solid phase extraction for clean-up procedure in application with LC-MS techniques, use of zwitterionic HILIC stationary phase along with MS as well as use of light scattering techniques has future scope for AG estimation.

The varieties of buffer mediums are available for AG estimation in various samples based on stability as well as ability for ion pairing. The selection of specific buffer medium is depends upon the analytical technique and sample stability. The various media used in AG analysis are shown in Table 3. Varieties of analytical techniques are available for the quantitative analysis of AGs. Choice of specific technique depends on the sensitivity, selectivity, time, and economy. As extensive data of various analytical techniques are available on quantitation of AGs from variety of samples, that found to be quite difficult correlate and compare. Thus, in this review the specific analytical data of RPHPLC of various AGs with their internal standards, limits of detection (LOD), limits of quantification (LOQ), and retention time have been depicted in Table 4 .

\section{Stability indicating analytical techniques for AGs}

Stability is the major concern of any drug in its dosage form during the storage period. International Conference on Harmonization guidelines provides the specific stability indicating protocol for AGs in pure as well as in pharmaceutical dosage forms. The most preferred technique is force degradation studies under

Table 3. Various types of media used for AG detection.

\begin{tabular}{|c|c|c|c|c|}
\hline Type of detection & Analytes & Method & Medium used & Refrences \\
\hline In-vitro & $\begin{array}{l}\text { Standards and } \\
\text { test solutions }\end{array}$ & HPLC & $\begin{array}{l}\text { Heptafluorobutyric acid (HFBA); ammonium } \\
\text { formate; formic acid (FA); sodium sulphate, sodium } \\
\text { octanesulphate and phosphate buffer mixture; } \\
\text { ammonium acetate; ammonium formate }\end{array}$ & $\begin{array}{l}\text { Megoulas and Koupparis, 2005; } \\
\text { Wei et al., 2014; Adams et al., } \\
\text { 1997; Cheng et al., 2010; Lee et al., } \\
\text { 2016; Zhang et al., } 2019\end{array}$ \\
\hline Ex vivo & Cell analytes & Immunofluoroscence & $\begin{array}{l}\text { Minimal essential medium (MEM) and saline } \\
\text { phosphate buffer; TRIS buffer; }\end{array}$ & $\begin{array}{l}\text { Myrdal et al., 2005; Karasawa } \\
\text { et al., } 2008\end{array}$ \\
\hline \multirow[t]{2}{*}{ In-vivo } & $\begin{array}{l}\text { Organ extract, } \\
\text { chicken meat, } \\
\text { human plasma, } \\
\text { milk, egg }\end{array}$ & LC-MS & $\begin{array}{l}\text { HFBA; HFBA and FA mixture; tetrafluoroacetic } \\
\text { acid; ammonium acetate; ammonium formate }\end{array}$ & $\begin{array}{l}\text { Zhu et al., 2008; Bousova et al., } \\
\text { 2013; Tao et al. 2012; Wang et al., } \\
\text { 2016; Kumar et al., 2011; Zhang } \\
\text { et al., } 2019\end{array}$ \\
\hline & Plasma and milk & ELISA, Radioimmunoassay & TRIS-HCl, saline phosphate buffer & $\begin{array}{l}\text { Jin et al., 2006a; Dols and Van } \\
\text { Zanten, } 1981\end{array}$ \\
\hline
\end{tabular}

Table 4. Various analytical details of AGs by RP-HPLC technique.

\begin{tabular}{|c|c|c|c|c|c|}
\hline Types of AG & $\begin{array}{l}\text { Internal standards } \\
\text { used }\end{array}$ & LOD & LOQ & $\begin{array}{c}\text { Retention Time } \\
\text { (Min) }\end{array}$ & Reference \\
\hline Gentamycin & Tobramycin & $25 \mu \mathrm{g} / \mathrm{kg}$ & $50 \mu \mathrm{g} / \mathrm{kg}$ & 6 & Salah et al., 2015 \\
\hline Tobramycin & Gentamycin $\mathrm{C} 1$ & $3 \mathrm{mg} / \mathrm{l}$ & $10 \mathrm{mg} / 1$ & 3 & Blanchaert et al., 2017 \\
\hline Amikacin & Gentamycin $\mathrm{C} 1$ & $0.5 \mathrm{mg} / \mathrm{l}$ & $1.5 \mathrm{mg} / 1$ & 4.5 & Blanchaert et al., 2017 \\
\hline Streptomycin & Dihydrostreptomycin & $0.5 \mu \mathrm{g} / \mathrm{ml}$ & $3 \mu \mathrm{g} / \mathrm{ml}$ & 6.10 & Granados et al., 2007 \\
\hline Kanamycin & Tobramycin & $15 \mathrm{ng} / \mathrm{g}$ & $25 \mathrm{ng} / \mathrm{g}$ & 8.5 & Zhang et al., 2019 \\
\hline Neomycin & Amikacin & $0.02 \mu \mathrm{g} / \mathrm{ml}$ & $0.06 \mu \mathrm{g} / \mathrm{ml}$ & 3.30 & Balaswami et al., 2018 \\
\hline
\end{tabular}


thermal, photolytic, acidic, alkaline, and oxidizing conditions. The thermal degradation $\mathrm{AG}$ will be conducted at $70^{\circ} \mathrm{C}$ for 48 hours. In case of photo-degradation studies, specific amount of AG solution will be exposed to sunlight for 48 hours. The drug will be heated at $0.1 \mathrm{MHCl}$ at $80^{\circ} \mathrm{C}$ for 2 hours under reflux for acid degradation. For alkaline degradation, the drug will be treated at $80 \mathrm{oC}$ with 0.1 $\mathrm{M} \mathrm{NaOH}$ for 2 hours, whereas in case of oxidative degradation, the drug will be heated with $\mathrm{H}_{2} \mathrm{O}_{2}$ at $80^{\circ} \mathrm{C}$ for 2 hours under reflux (Blanchaert et al., 2017).

\section{Qualitative methods}

The qualitative method used for AG analysis includes $\mathrm{X}$-ray crystallography, nuclear magnetic resonance, mass spectroscopy. The preparation of purified AG form amorphous solid, hence not suitable for aminoglycoside analysis. The proton and $13 \mathrm{C}$-NMR spectroscopic methods are used for structural determination of AG. MS is also used in structural and enzyme modified analysis. Recently, a study has reported the use of fast atom bombardment or electron spray with tandem MS in the determination of positional isomers of kanamycin A (Cox and Serpersu, 1995; Kotretsou and Constantinou-Kokotou, 1998).

\section{CONCLUSION}

Although newer and less toxic antimicrobials are introduced into the market, the AG remains to be the drug of choice for serious infection due to Gram-negative bacteria. AG being a potent class of antibiotics with a shorter therapeutic window and potential side effects. Constant monitoring on its level of presence in the biological system needs to be done. For this reason, a simple, economic, and relatively fast analytical method for routine analysis is required. Although microbial assay is but it lacks specificity, accuracy, and may subject to interference, so the chromatographic method remains as a better choice to meet the requirement. The detector of interest is based on availability and financial aspect, due to the absence of chromophore UV is not a common method of choice and thus, its properties restrict the use of common RP-HPLC method. Hence, there is a huge potential gap in AG analysis where more research can be carried out. The use of combination of chromatographic techniques along with mass spectroscopy will be the best methods for AG quantification.

\section{CONFLICT OF INTEREST}

The authors declare that they have no conflict of interest.

\section{FUNDING}

None.

\section{REFERENCES}

Adams E, Dalle J, De BE, De SI, Roets E, Hoogmartens J. Analysis of kanamycin sulfate by liquid chromatography with pulsed electrochemical detection. J Chromatogr A, 1997; 766:133-9.

Balaswami B, Beddakotla VR, Bandi SR, Pagidirai S. A new stebility indicating RP-HPLC-PDA method for simultaneous estimation of neomycin and fluocinolone in pharmaceutical tablet dosage form. Int J Pharm Sci Res, 2018; 9(10):4187-893.

Blanchaert B, Huang S, Wach K, Adams E, Van Schepdael A. Assay development for aminoglycosides by HPLC with direct UV detection. J Chromatogr Sci, 2017; 55(3):197-204.
Bohm DA, Stachel CS, Gowik P. Confirmatory method for the determination of streptomycin and dihydrostreptomycin in honey by LCMS/MS. Food Addit Contam Part A, 2012; 29(2):189-96.

Bohm DA, Stachel CS, Gowik P. Validation of a method for the determination of aminoglycosides in different matrices and species based on an in-house concept. Food Addit Contam Part A, 2013; 30(6):1037-43.

Bousova K, Senyuva H, Mittendorf K. Quantitative multiresidue method for determination antibiotics in chicken meat using turbulent flow chromatography coupled to liquid chromatography-tandem mass spectrometry. J Chromatogr A, 2013; 1274:19-27.

Brion F, Nilsen BM, Eidem JK, Goksøyr A, Porcher JM. Development and validation of an enzyme-linked immunosorbent assay to measure vitellogenin in the zebrafish (Danio rerio). Environ Toxicol Chem, 2002; 21(8):1699-708

Broughton A, Strong JE, Pickering LK, Bodey GP Radioimmunoassay of iodinated tobramycin. Antimicrob Agents Chemother, 1976; 10(4):652-6.

Carlier M, Stove V, Wallis SC, De Waele JJ, Verstraete AG, Lipman J, Roberts JA. Assays for therapeutic drug monitoring of $\beta$-lactam antibiotics: a structured review. Int J Antimicrob Agents, 2015; 46(4):367-75.

Chen Y, Shang Y, Li X, Wu X, Xiao X. Development of an enzyme-linked immunoassay for the detection of gentamicin in swine tissues. Food Chem, 2008; 108(1):304-9.

Cheng C, Liu S, Xiao D, Hansel S. The application of trichloroacetic acid as an ion pairing reagent in LC-MS-MS method development for highly polar aminoglycoside compounds. Chromatographia, 2010; 72:133-9.

Clarot I, Chaimbault P, Hasdenteufel F, Netter P, Nicolas A Determination of gentamicin sulfate and related compounds by highperformance liquid chromatography with evaporative light scattering detection. J Chromatogr A, 2004; 1031(1-2):281-7.

Coppex L, Walz R. Derivatives for HPLC analysis, 2000. [ONLINE] Available via http://www. sigmaaldrich. com/img/assets/22084/ HPCL_Derivatization_Literature pdf. (Accessed 14 May 2019).

Cox JR, Serpersu EH. The complete 1H NMR assignments of aminoglycoside antibiotics and conformational studies of butirosin through the use of 2D NMR spectroscopy. Carbohydr Res, 1995; 271(1):55-63.

Di Corcia A, Nazzari M. Liquid chromatographic-mass spectrometric methods for analyzing antibiotic and antibacterial agents in animal food products. J Chromatogr A, 2002; 974(1):53-89.

Dijkstra JA, Sturkenboom MG, Hateren KV, Koster RA, Greijdanus B, Alffenaar JW. Quantification of amikacin and kanamycin in serum using a simple and validated LC-MS/MS method. Bioanalysis, 2014; 6(16):2125-33.

Dijkstra JA, Voerman AJ, Greijdanus B, Touw DJ, Alffenaar JW Immunoassay analysis of kanamycin in serum using the tobramycin kit Antimicrob Agent Chemother, 2016; 60(8):4646-51.

Dols JL, Van Zanten AP. Gentamicin assay: comparison of an adapted EMIT method and an RIA method. Ann Clin Biochem, 1981; 18(4):236-9.

Farouk F, Azzazy HM, Niessen WM. Challenges in the determination of aminoglycoside antibiotics, a review. Anal Chim Acta, 2015; 890:21-43.

Ferguson JP, Baxter GA, McEvoy JD, Stead S, Rawlings E, Sharman M. Detection of streptomycin and dihydrostreptomycin residues in milk, honey and meat samples using an optical biosensor. Analyst, 2002; 127(7):951-6.

Forge A, Schacht J. Aminoglycoside antibiotics. Audiol Neurotol, 2000; 5(1):3-22.

Fraihat SM. New extractive colorimetric method for the assay of gentamicin and streptomycin using ion-pair association complexes. Eurasian J Anal Chem, 2015; 10(3):180-6.

Granados O, Meza G. A direct HPLC method to estimate streptomycin and its putative ototoxic derivative, streptidine, in blood serum: application to streptomycin-treated humans. J Pharm Biomed Anal, 2007; 43(2):625-30. 
Gunawardana G, Childress C, Tripp M, Zhang X, West P. The identification of 1, 6'-and 1, 3"-Di-N-(L-4-amino-2-hydroxybutyryI) derivatives of kanamycin as synthetic byproducts of amikacin. J Antibiot, 1997; 50(10):887-9.

Guo MX, Wrisley L, Maygoo E. Measurement of tobramycin by reversed-phase high-performance liquid chromatography with mass spectrometry detection. Anal Chim Acta, 2006; 571(1):12-6.

Holzgrabe U, Nap C, Kunz N, Almeling S. Identification and control of impurities in streptomycin sulfate by high-performance liquid chromatography coupled with mass detection and corona charged-aerosol detection. J Pharm Biomed Anal, 2011; 56:271-9.

Hubicka U, Witek ZB, Piotrowska JO, Krzek J. Determination of neomycin in the form of neomycin derivative with dabsyl chloride by thin layer chromatography and densitometry. Acta Pol Pharm, 2015; 72:31-7.

Hussien MA, Adam ME, Shantier SW, Garalnabi EA, Gadkariem EA. Development and validation of colorimetric method for the quantitative analysis of kanamycin in bulk and pharmaceutical formulation. J Appl Pharm Sci, 2017; 7(4):163-7.

Isoherranen N, Soback S. Chromatographic methods for analysis of aminoglycoside antibiotics. J AOAC Int, 1999; 82:1017-45.

Jiang L, Wei D, Zeng K, Shao J, Zhu F, Du D. An enhanced direct competitive immunoassay for the detection of kanamycin and tobramycin in milk using multienzyme-particle amplification. Food Anal Method, 2018; 11(8):2066-75.

Jiang Y, Sun DW, Pu H, Wei Q. Ultrasensitive analysis of kanamycin residue in milk by SERS-based aptasensor. Talanta, 2019; 197:151-8.

Jin Y, Jang JW, Han CH, Lee MH. Development of immunoassays for the detection of kanamycin in veterinary fields. J Vet Sci, 2006a; $7(2): 111-7$

Jin Y, Jang JW, Lee MH, Han CH. Development of ELISA and immunochromatographic assay for the detection of neomycin. Clin Chim Acta, 2006b; 364(1-2):260-6.

Karasawa T, Wang Q, Fu Y, Cohen DM, Steyger PS. TRPV4 enhances the cellular uptake of aminoglycoside antibiotics. J Cell Sci, 2008; 121(17):2871-9.

Kotretsou SI, Constantinou-Kokotou V. Mass spectrometric studies on the fragmentation and structural characterization of aminoacyl derivatives of kanamycin A. Carbohydr Res, 1998; 310(1-2):121-7.

Kowalczuk D, Pietraś R, Paw B, Czerkies A. Applying liquid chromatography with fluorescence detection to determine gentamicin. Pol J Environ Stud, 2010; 19(3):587-91.

Krause KM, Serio AW, Kane TR, Connolly LE. Aminoglycosides: an overview. Cold Spring Harb Perspect Med, 2016; 6(6):a027029.

Kumar GA, Ramya V. Quantification of Gentamicin by microbial assay technique and reverse phase HPLC. Euro J Exp Bio, 2012; 2(6):2083-9.

Kumar P, Rubies A, Companyo R, Centrich F. Hydrophilic interaction chromatography for the analysis of aminoglycosides. J Sep Sci, 2011; 35:498-504.

Lee K, Jun SH, Han M, Song SH, Park JS, Lee JH, Park KU, Song J. Multiplex assay of second-line anti-tuberculosis drugs in dried blood spots using ultra-performance liquid chromatography-tandem mass spectrometry. Ann Lab Med, 2016; 36:489-93.

Li RG, Hurum D, Wang JL, Rohrer J. Gentamicin sulfate assay by HPLC with charged aerosol detection, 2012. [ONLINE] Available via http://www.bargal.co.il/loadedFiles/7.pdf. (Accessed 13 May 2019).

Loomans EE, van Wiltenburg J, Koets M, van Amerongen A. Neamin as an immunogen for the development of a generic ELISA detecting gentamicin, kanamycin, and neomycin in milk. J Agric Food Chem, 2003; 51(3):587-93.

McGlinchey $\mathrm{T}$. The determination of veterinary antibiotics in live animals and animal products. Doctoral dissertation, Dublin City University, 2011.

McGlinchey TA, Rafter PA, Regan F, McMahon GP. A review of analytical methods for the determination of aminoglycoside and macrolide residues in food matrices. Anal Chim Acta, 2008; 624(1):1-5.
Megoulas NC, Koupparis MA. Development and validation of a novel HPLC/ELSD method for the direct determination of tobramycin in pharmaceuticals, plasma, and urine. Anal Bioanal Chem, 2005a; 382(2):290-6.

Megoulas NC, Koupparis MA. Direct determination of kanamycin in raw materials, veterinary formulation and culture media using a novel liquid chromatography-evaporative light scattering method. Anal Chim Acta, 2005b; 547:64-72.

Mucklow J. Modern pharmacology with clinical applications. Br J Clin Pharmacol, 2004; 58(3):337.

Myrdal SE, Johnson KC, Steyger PS. Cytoplasmic and intranuclear binding of gentamicin does not require endocytosis. Hear Res, 2005; 204(1):156-69.

Omar MA, Nagy DM, Hammad MA, Aly AA. Highly sensitive spectrofluorimetric method for determination of certain aminoglycosides in pharmaceutical formulations and human plasma. AAPS PharmSciTech, 2013; 14(2):828-37.

Pang G, Zhang J, Cao Y, Fan C, Lin X, Li Z, Jia G. Evaluation of analyte stability and method ruggedness in the determination of streptomycin residue in honey by liquid chromatography with post-column derivatization. J AOAC Int, 2004; 87:39-44.

Pavlov A, Lashev L, Rusev V. Studies on the residue levels of tobramycin in stored poultry products. Trakia J Sci, 2005; 3(5):5.

Reeves DS. Therapeutic drug monitoring of aminoglycoside antibiotics. Infection, 1980; 8(3):S313-20.

Ruckmani K, Shaikh SZ, Khalil P, Muneera MS. A simple and rapid high-performance liquid chromatographic method for determining tobramycin in pharmaceutical formulations by direct UV detection. Pharma Methods, 2011; 2(2):117-23.

Salah H, Hassan M, Amro FH. Validation of a RP-HPLC method for estimation of Gentamycin sulfate in poultry meat using UV detector. Egypt J Chem Environ Health, 2015; 1(1):955-70.

Samain D, Dupin P, Delrieu P, Inchauspe G. Multidimensional ion-pair HPLC for the purification of aminoglycoside antibiotics with refractive index detection. Chromatographia 1987; 24(1):748-52.

Santos L, Ramos F. Analytical strategies for the detection and quantification of antibiotic residues in aquaculture fishes: a review. Trends Food Sci Technol, 2016; 52:16-30.

Stead DA. Current methodologies for the analysis of aminoglycosides. J Chromatogr B Biomed Sci Appl, 2000; 747(1-2):69-93.

Stypulkowska K, Blazewicz A, Fijalek Z, Sarna K Determination of gentamicin sulphate composition and related substances in pharmaceutical preparations by LC with charged aerosol detection. Chromatographia, 2010; 72(11-12):1225-9.

Tan L, Wlasichuk K, Schmidt D, Campbell R, Hirtzer P, Cheng L, Karr D. A high $\mathrm{pH}$ based reversed-phase high performance liquid chromatographic method for the analysis of aminoglycoside plazomicin and its impurities. J Pharm Biomed Anal, 2012; 66:75-84.

Tan X, Jiang YW, Huang YJ, Hu SH. Persistence of gentamicin residues in milk after the intramammary treatment of lactating cows for mastitis. J Zhejiang Univ-Sci B, 2009; 10(4):280-4.

Tao Y, Chen D, Yu H, Huang L, Liu Z, Cao X, Yan C, Pan Y, Liu Z, Yuan Z. Simultaneous determination of 15 aminoglycoside(s) residues in animal derived foods by automated solid-phase extraction and liquid chromatography-tandem mass spectrometry. Food Chem, 2012; 135 $676-83$.

Tawa R, Matsunaga H, Fujimoto T. High-performance liquid chromatographic analysis of aminoglycoside antibiotics. J Chromatog A, 1998; 812(1-2):141-50.

Teja GS, Gurupadayya BM, Sairam KV. Analytical method development and validation of amikacin in pure and marketed formulation using HPLC. Int J Pharm Sci Res, 2018; 9(10):4382-6.

Wang Y, Li S, Zhang F, Lu Y, Yang B, Zhang F, Liang X. Study of matrix effects for liquid chromatography-electrospray ionization tandem mass spectrometric analysis of 4 aminoglycosides residues in milk. J Chromatogr A, 2016; 1437:8-14. 
Wei J, Shen A, Wan H, Yan J, Yang B, Guo Z, Zhang F, Liang X. Highly selective separation of aminoglycoside antibiotics on a zwitterionic Click TE-Cys column. J Sep Sci, 2014; 37:1781-7.

Yamamoto CH, Pinto TJ. Rapid determination of neomycin by a microbiological agar diffusion assay using triphenyltetrazolium chloride. J AOAC Int, 1996; 79(2):434-40.

Zhang QM, Zhang ZX. HPLC-ELSD determination of neomycin sulfate and its related substance neamine. Chin J Pharm Anal, 2007; 27(2):212-5.

Zhang X, Wang J, Wu Q, Li L, Wang Y, Yang H. Determination of Kanamycin by High Performance Liquid Chromatography. Molecules, 2019; 24(10):1902.

Zhu L. Determination of kanamycin sulfate injection by HPLCNQAD and HPLC-ELSD. Chin J Pharm Anal, 2014; 34(4):644-8.
Zhu WX, Yang JZ, Wei W, Liu YF, Zhang SS. Simultaneous determination of 13 aminoglycoside residues in foods of animal origin by liquid chromatography-electrospray ionization tandem mass spectrometry with two consecutive solid-phase extraction steps. J Chromatogr A, 2008; 1207:29-37.

\section{How to cite this article:}

Hari R, Taherunnisa S, Raut SY, Mutalik S, Koteshwara KB. Challenges in the development of analytical test procedure for aminoglycosides: A critical review. J Appl Pharm Sci, 2019; 9(11):145-152. 